\title{
Do reduced levels of steroid 21-hydroxylase confer a survival advantage in fetuses affected by sex chromosome aberrations?
}

\author{
Vilma Mantovani ${ }^{*}$, Elisabetta Dondi $^{2}$, Daniela Larizza ${ }^{3}$, Mariangela Cisternino ${ }^{3}$, \\ Michela Bragliani ${ }^{1}$, Mariagabriella Viggiani ${ }^{1}$, Miryam Martinetti ${ }^{4}$ and Mariaclara Cuccia ${ }^{2}$
}

${ }^{1}$ Laboratorio Centralizzato Settore Genetica, Policlinico S.Orsola-Malpighi, Bologna, Italy; ${ }^{2}$ Dipartimento di Genetica e Microbiologia, Università di Pavia, Pavia, Italy; ${ }^{3}$ Dipartimento di Scienze Pediatriche, Università di Pavia; IRCCS Policlinico S.Matteo, Pavia, Italy; ${ }^{4}$ Laboratorio HLA, Servizio di Immunoematologia e Trasfusione, IRCCS Policlinico S. Matteo, Pavia, Italy

We investigated whether molecular defects in the CYP21 gene were detectable in two common sex chromosome aberrations, the Turner and the Klinefelter syndromes. We found abnormal 17hydroxyprogesterone levels after adrenal stimulation in $26 / 60(43.3 \%)$ patients affected by these chromosome aberrations, as compared with only $11 / 68(16.2 \%)$ normal controls $(P=0.0014$, odds ratio 4.0$)$. Screening of the CYP21 gene identified a single Val281Leu missense mutation in exon 7 in 9/63 (14.3\%) of the patients, all nine of whom were heterozygote carriers; the mutation frequency was significantly higher than in the general population $(P=0.007$, odds ratio=3.5). The hormonal and molecular data indicate that these common sex chromosome aberrations are associated with a remarkably high frequency of steroidogenic defects. It may be hypothesised that reduced levels of steroid 21-hydroxylase could confer a survival advantage, leading to a successful pregnancy.

European Journal of Human Genetics (2002) 10, 137 -140. DOI: 10.1038/sj/ejhg/5200778

Keywords: steroid 21-hydroxylase deficiency; Klinefelter syndrome; Turner syndrome; CYP21 gene; steroid 21-hydroxylase; sex chromosomes

\section{Introduction}

Steroid 21-hydroxylase $(21-\mathrm{OH})$ is a microsomal cytochrome P450 required for glucocorticoid and mineralocorticoid synthesis within the adrenal cortex. The 21-OH deficiency is the main cause of congenital adrenal hyperplasia $(\mathrm{CAH})$, a recessive genetic disease due to mutations of the CYP21 gene that lead to steroid imbalance. ${ }^{1} \mathrm{CAH}$ owing to $21-\mathrm{OH}$ deficiency has been reported in four patients with Turner syndrome. $^{2-5}$ In keeping with these observations, we previously reported hormonal and biochemical data reveal-

*Correspondence: V Mantovani, Laboratorio Centralizzato Settore Genetica, Policlinico S.Orsola-Malpighi, Via Massarenti, 9, 40138 Bologna Italy. Tel: +39 051 6364455; Fax: +39051 6363851;

E-mail: mantovan@med.unibo.it

Received 20 January 2001; revised 18 December 2001; accepted 4 January 2002 ing a high frequency of suspected heterozygote carriers of CYP21 defects in Turner syndrome patients and in their relatives. ${ }^{6}$ Herein we report the results of a molecular study undertaken on a group of patients affected by Turner syndrome and on a group of Klinefelter syndrome patients. Part of the Turner syndrome data were presented during the Twelfth International Histocompatibility Workshop. ${ }^{7}$ The aim of the study was to investigate whether molecular defects in the CYP21 gene were detectable in these common sex chromosome aberrations.

Materials and methods

Patients and controls

The study regarded 48 Turner syndrome patients (thirty-two with a $45, \mathrm{X}$ karyotype, 14 with mosaicism and/or structural abnormalities of the $\mathrm{X}$ chromosome and one with mosaicism 
including $\mathrm{Y}$ chromosome) and 15 Klinefelter syndrome patients (14 with 47,XXY karyotype and one with 49,XXXXY karyotype). All the patients originated from northern Italy and attended regular follow-up in the Endocrinological Clinic of the Department of Pediatrics of the University of Pavia.

Despite the high prevalence of the Klinefelter syndrome, a relatively low number of cases was included in the study because, unlike the Turner syndrome, this disorder, is usually ascertained in adult age. Except for one girl with Turner syndrome who had had clinically evident clitoromegaly from birth, none of the patients presented clinical signs suggesting CAH. As controls, 349 blood donors were enrolled, having been carefully screened to ensure that they all shared the northern Italian provenance of the patients. Informed consent was obtained for all subjects submitted to study.

\section{Hormonal investigation}

The hormonal investigation was carried out in all the patients with the exception of one Turner syndrome patient who presented high baseline 17-hydroxyprogesterone (17$\mathrm{OHP}$ ) serum levels (>10000 ng/dL) and three Klinefelter syndrome patients. Among the 349 controls, 68 randomly selected subjects underwent hormonal investigation. Blood samples were drawn at 0 and 60 min after administration of synthetic ACTH (0.25 mg Synacthen, Ciba, Basel) and assayed for 17-OHP levels. To identify presumed heterozygotes for CYP21 gene defects, a cut-off point of $350 \mathrm{ng} / \mathrm{dL}$ of 17-OHP measured at $60 \mathrm{~min}$ after ACTH stimulation was adopted for the Turner syndrome patients, as previously described; ${ }^{6}$ for the Klinefelter syndrome patients, the cut-off point was $305 \mathrm{ng} / \mathrm{dL}^{8}$ These values corresponded to the mean $\pm 2 \mathrm{SD}$ of the values recorded in the control group.

\section{Molecular analysis}

Extensive molecular analysis of the CYP21 gene was performed on those Turner patients who showed reduced levels of 21-OH at hormonal investigation. Large rearrangements were studied by Southern blot analysis, using TaqIrestricted DNA hybridised with $\mathrm{C} 4 \mathrm{cDNA}$ and CYP21 probes. CYP21 exons, exon-intron junctions and the -300 bp $5^{\prime}$ promoter region were sequenced using an automated sequencer (Applied Biosystems, Foster City, CA, USA), as described by Blanché et al. ${ }^{9}$ The remaining Turner syndrome patients, all the Klinefelter syndrome patients, and the control samples, were screened only for presence of the Val281Leu mutation in exon 7. After specific CYP21 gene amplification (using primers 5'- TTG TCC TTG GGA GAC TAC TCC $-3^{\prime}$ and 5'- GCT CGG GCT TTC CTC ACT CA -3'), sequence specific oligonucleotide hybridisations with wildtype (5'- AAG GGC ACG TGC ACA TG -3') and mutated (5'AAG GGC ACT TGC ACA TG -3') DIG-ddUTP labelled probes were performed. The positive samples were confirmed by restriction analysis of amplified fragments using the PmlI enzyme, the restriction site of which is eliminated by mutation.

\section{Statistical analysis}

Statistical analysis was performed using Fisher's exact test or Yates' corrected Chi-square and calculating odds ratio (OR) from $2 \times 2$ contingency tables.

\section{Results}

The results of hormonal and molecular analysis are shown in Table 1. Among the Turner syndrome patients, abnormal 17 OHP response was present in $17 / 48$ (35.4\%) cases. In 16 patients, the ACTH stimulation test values suggested a profile of heterozygosity for CYP21 mutation, while the remaining subject had a very high baseline 17-OHP level and was diagnosed as having the simple virilising (SV) form of 21-OH deficiency. ${ }^{1}$ Screening of the whole CYP21 gene, which was performed for all these 17 patients, enabled the identification of a single missense mutation in exon 7, Val281Leu. This was identified as being heterozygous in six patients, including the one affected by the SV form. No other mutations of the CYP21 gene were found. None of the 31 Turner syndrome patients with normal hormonal values turned out to have the Val281Leu mutation.

Among the 12 Klinefelter syndrome patients in whom the ACTH stimulation test was performed, an abnormal 17-OHP response was revealed in nine (75\%) cases. Molecular analysis of CYP21 gene revealed that three (20\%) of the fifteen Klinefelter syndrome patients included in the study were

Table 1 Frequency of patients and controls exhibiting abnormal 17-hydroxyprogesterone response to adrenal stimulation (positive ACTH test), and frequency of heterozygote carriers of CYP21 Val281Leu mutation found in patients and controls

\begin{tabular}{|c|c|c|c|c|c|c|c|c|c|c|c|c|}
\hline & \multicolumn{2}{|c|}{$\begin{array}{c}\text { Positive } \\
\text { ACTH test }\end{array}$} & \multirow[b]{2}{*}{$P^{*}$} & \multirow[b]{2}{*}{$O R^{*}$} & \multicolumn{2}{|c|}{$\begin{array}{c}\text { Val281Leu } \\
\text { carriers }\end{array}$} & \multirow[b]{2}{*}{$p^{*}$} & \multirow[b]{2}{*}{$O R^{*}$} & \multirow{2}{*}{$\begin{array}{c}\text { Positive ACTH } \\
\text { test-negative } \\
\text { Val281 Leu } \\
N\end{array}$} & \multirow[b]{2}{*}{$\%$} & \multirow[b]{2}{*}{$P^{*}$} & \multirow[b]{2}{*}{$O R^{*}$} \\
\hline & $N$ & $\%$ & & & $N$ & $\%$ & & & & & & \\
\hline Turner patients & $17 / 48$ & 35.4 & 0.0304 & 2.8 & $6 / 48$ & 12.5 & 0.037 & 3.0 & $11 / 48$ & 22.9 & 0.17 & 2.2 \\
\hline Klinefelter patients & $9 / 12$ & 75.0 & 0.0001 & 15.6 & $3 / 15$ & 20.0 & 0.036 & 5.2 & $6 / 12$ & 50.0 & 0.0051 & 7.5 \\
\hline Total patients & $26 / 60$ & 43.3 & 0.0014 & 4.0 & $9 / 63$ & 14.3 & 0.007 & 3.5 & $17 / 60$ & 28.3 & 0.032 & 3.0 \\
\hline Controls & $11 / 68$ & 16.2 & - & - & $16 / 349$ & 4.6 & - & - & $8 / 68$ & 11.8 & - & - \\
\hline
\end{tabular}

* The $P$ and OR (odds ratio) values were calculated comparing each group of patients versus the controls. 
carriers of the Val281Leu mutation. All these three patients had been positive at the ACTH test.

Among the 68 control subjects in whom the Synacthen test was performed, only $11(16.2 \%)$ had values corresponding to the heterozygous condition of 21-OH deficiency. Statistical analysis showed that this rate was significantly lower than the overall frequency $(26 / 60,43.3 \%)$ recorded in the patients with Turner or Klinefelter syndrome $(P=0.0014, \mathrm{OR}=4.0)$.

Screening for the Val281Leu mutation, which was performed for all 349 control subjects (including the 68 submitted to ACTH test), showed a mutation frequency of $4.6 \%$ (16/349). Among the 16 controls carrying the Val281Leu mutation, three happened to be included in the group submitted to hormonal test; all three had reduced 21$\mathrm{OH}$ levels. These data are in agreement with those previously reported for Italian population. ${ }^{10}$

As can be seen from Table 1, statistical analysis showed that the mutation frequency was significantly higher in the patients affected by Turner or Klinefelter syndrome than in the controls $(9 / 63,14.3 \%$ vs 16/349, 4.6\%; $P=0.007$, OR=3.5). The excess in patients with positive ACTH test remained statistically significant overall (and for the Klinefelter subgroup), even when the subjects with a demonstrated mutation were excluded $(17 / 60,28.3 \%$ vs $8 / 68,11.8 \%$ : $P=0.032$, OR=3.0).

Comparison of the clinical and anamnestic characteristics of the Turner/Klinefelter syndrome patients with and without the Val281Leu mutation could not reveal any association with presence of clinical signs at diagnosis, parental age, parental fertility, family history of pregnancy failure or congenital malformations (data not shown).

\section{Discussion}

The hormonal and molecular data from the present study reveal a remarkably high frequency of steroidogenic defects in subjects affected by Turner and Klinefelter syndromes, two common sex chromosome aberrations. The frequences of patients showing an abnormal 17-OHP response to ACTH test (43.3\%) and carrying CYP21 gene mutation (14.3\%) were both significantly higher than those found among healthy controls (16.2\%, $P=0.0014$ and $4.6 \%, P=0.007$, respectively).

To our knowledge, apart from a unique case of CAH in Klinefelter syndrome described in Japan, ${ }^{11}$ this is the first time that an association has been reported between reduced levels of 21-OH and Klinefelter syndrome. Precocious puberty is thought to occur more frequently in boys affected by Klinefelter syndrome than would be expected by chance. ${ }^{12,13}$ Since true precocious puberty has been associated with heterozygosity for CYP21 gene mutations, ${ }^{7,8}$ our results regarding Klinefelter syndrome could also explain the increased frequency of sexual precocity found in this syndrome. In addition, our results confirm on a molecular level our previously reported hormonal and biochemical data in patients with Turner syndrome. ${ }^{6}$
The extensive molecular screening of the CYP21 gene, initially performed in the Turner patients, revealed only the missense Val281Leu mutation. This codon 281 mutation, usually found in association with the HLA-B14, DR1 haplotype, is the most frequent mutation causing the lateonset form 21-OH deficiency. Val281Leu mutation results in an enzyme with $50 \%$ of normal activity when $17-\mathrm{OHP}$ is the substrate, but only $20 \%$ of normal activity for progesterone. ${ }^{14}$

Lack of detectable mutations in the entire CYP21 gene has also been reported in patients suffering from CAH. ${ }^{15}$ Independent studies on Italian, Spanish and French patients report frequencies of alleles without mutations ranging between 11 and 22\%, and that the finding is more common in the non-classical form of the disease. ${ }^{16-18}$

Molecular defects in other promoter/regulatory regions controlling the transcription of CYP21 or defects in genes of other steroidogenic enzymes could be involved, and further studies are needed to clarify this possibility. Since the excess in patients with positive ACTH test remained statistically significant when the subjects with Val281Leu mutation were excluded, the effect could be exerted by additional genes.

It is not easy to suggest even a tentative explanation of our findings. A causal relationship is not necessarily implicated between the CYP21 mutation itself and the non-disjunction defect. As we identified just one single type of CYP21 mutation, it is possible another gene on the same Val281Leu haplotype could be responsible for modifying the risk of nondisjunction. A more attractive hypothesis could be that the reduced levels of steroid 21-OH afford a survival advantage in fetuses affected by chromosome aberrations. It is well known that only a small proportion of conceptions in humans result in live births. The frequency of spontaneous abortion, including the proportion of preclinical pregnancy loss, is estimated to vary from 18.5 to $74 \%$. Up to half of the recognised spontaneous abortions have chromosomal abnormalities, and many of the remaining ones have recognisable malformations, ${ }^{19}$ indicating that mothers possess an efficient screening system to eliminate genetically abnormal embryos. Early embryonic signals (eg human chorionic gonadotropin and alpha-fetoprotein) probably provide biochemical cues that the mother's organism uses to assess offspring quality. ${ }^{20}$

A major intrauterine selection against the 45 , X karyotype is well known: more than $90 \%$ of the conceptions with this karyotype end in spontaneous abortion. While the reported frequency of 47,XXY karyotype is one in 1000 among all conceptions, it is only one in 2000 among consecutive newborns, indicating a foetal loss rate of about $50 \% .^{21}$ As intrauterine selection exists (albeit to different extents) against both Turner and Klinefelter syndromes, even a small selective advantage in pregnancy could be relevant. We could speculate that the fine balance between the embryo and mother could be modified by endocrine cues deriving from embryos with reduced levels of steroid 21-OH, causing relaxation of the maternal screening. 
Recently, Witchel et $a l^{22}$ found significantly elevated cortisol responses after ACTH stimulation in carriers of 21$\mathrm{OH}$ defects, as compared with healthy controls. They suggested the existence of a survival advantage in heterozygotes, due to their brisk cortisol response to infectious, inflammatory or other environmental stresses. A similar survival advantage conferred by reduced levels of $21-\mathrm{OH}$ could be hypothesised in foetuses affected by sex chromosome aberrations leading to successful birth rather than pregnancy failure. The beneficial effects mediated by steroid hormones following conception could act on the immunoregulatory mechanisms that enable the pregnancy. ${ }^{23}$

The results of the present study should fuel further investigation. The hypotheses suggested above could be additionally verified by investigating other sex chromosome aberrations for presence of adrenal steroid defects.

\section{Acknowledgments}

We are grateful to Robin M T Cooke for editing.

\section{References}

1 White PC, New MI: Genetic basis of endocrine disease: congenital adrenal hyperplasia due to 21-hydroxylase deficiency. J Clin Endocrinol Metab 1992; 74: 6-11.

2 Del Arbol J, Soto MJ, Fernandez AJ et al: Turner syndrome caused by deletion of long arm of the X chromosome associated with adrenogenital syndrome caused by partial deficiency of 21hydroxylase. Rev Clin Esp 1983; 171: 67 - 71.

3 Montemajor-Jauregui M, Ulloa-Gregori A, Flores-Briseno G: Associated adrenogenital and Turner's syndrome mosaicism. Plastic \& Reconstructive Surgery 1985; 75: 877-881.

4 Kuhnle U, Bidlingmaier F, Knorr D, Butenandt O, Peller P: Sex steroid dependent gonadotropin secretion in gonadal dysgenesis during early infancy: case study of an infant with gonadal dysgenesis (45.XO) and classical 21-hydroxylase deficiency. J Ped Endocrinol 1989; 3: 257-260.

5 Maciel-Guerra AT, Guerra JG, Marini SHVL, Baptista MTM, Marques-de-Faria AP: Female pseudohermaphroditism due to classical 21-hydroxylase deficiency in a girl with Turner syndrome. Clin Genet 1997; 51: 351-353.

6 Larizza D, Cuccia M, Martinetti M et al: Adrenocorticotrophin stimulation and HLA polymorphisms suggested a high frequency of heterozygosity for steroid 21-hydroxylase deficiency in patients with Turner's syndrome and their families. Clin Endocrinol 1994; 40: 39 - 45.
7 Cuccia M, Blanche H, Dolzan V et al: Mutations of CYP21 gene (MHC class III) in pathologies other than congenital adrenal hyperplasia (CAH); in Charron D (ed): Genetic diversity of HLA. Functional and medical implication. Paris: EDK, 1997, vol 1, pp $442-444$.

8 Cisternino M, Dondi E, Martinetti $\mathrm{M}$ et al: Exaggerated 17hydroxyprogesterone response to short-term adrenal stimulation and evidence for CYP21B gene point mutations in true precocious puberty. Clin Endocrinol 1998; 48: 555-560.

9 Blanchè $\mathrm{H}$, Vexiau $\mathrm{P}$, Clauin $\mathrm{S}$ et al: Exhaustive screening of the 21-hydroxylase gene in a population of hyperandrogenic women. Hum Genet 1997; 101: 56-90.

10 Speiser PW, Dupont B, Rubinstein P, Piazza A, Kastelan A, New MI: High frequency of nonclassical steroid 21-hydroxylase deficiency. Am J Hum Genet 1985; 37: 650-667.

11 Yamaguchi $\mathrm{T}$, Abe H, Kuwano T, Sugimoto T. Chihara K: Congenital adrenal hyperplasia with 47 , XXY Klinefelter syndrome. Exp Clin Endocrinol 1994; 102: 348-350.

12 von Mülendahl KE, Heinrich U: Sexual precocity in Klinefelter syndrome: report on two new cases with idiopathic central precocious puberty. Eur J Pediatr 1994; 153: 322 - 324.

13 Bertelloni S, Baroncelli GI, Battini R, Saggese G: Central precocious puberty in Klinefelter syndrome: a case report with longitudinal follow-up of growth pattern. Am J Med Genet 1996; 65: $52-55$.

14 White PC, Tusie-Luna MT, New MI, Speiser PW: Mutations in steroid 21-hydroxylase (CYP21). Hum Mutat 1994; 3: 373-378.

15 Nimkarn S, Cerame BI, Wei J et al: Congenital adrenal hyperplasia (21-hydroxylase deficiency) without demonstrable genetic mutations. J Clin Endocrinol Metab 1999; 84: 378 - 381.

16 Carrera P, Bordone L, Azzani T et al: Point mutations in Italian patients with classic, non classic and cryptic forms of steroid 21hydroxylase deficiency. Hum Genet 1996; 98: 662-665.

17 Ezquieda B, Oliver A, Gracia R, Gancedo PC: Analysis of steroid 21-hydroxylase gene mutations in the Spanish population. Hum Genet 1995; 96: $198-204$.

18 Barbat B, Bogyo A, Raux-Demay MC et al: Screening of CYP21 gene mutations in 129 French patients affected by steroid 21hydroxylase deficiency. Hum Mutat 1995; 5: 126-130.

19 Guerneri S, Bettio D, Simoni G, Brambati B, Lanzani A, Fraccaro $\mathrm{M}$ : Prevalence and distribution of chromosome abnormalities in a sample of first trimester internal abortions. Hum Reprod 1987; 2: $735-739$.

20 Forbes LS: The evolutionary biology of spontaneous abortion in humans. TREE 1997; 12: 446-450.

21 Hassold TY, Jacobs PA: Trisomy in man. Annu Rev Genet 1984; 18 69-97.

22 Witchel SF, Lee PA, Suda-Hartman M, Trucco M, Hoffman EP: Evidence for a heterozygote advantage in Congenital Adrenal Hyperplasia due to 21-Hydroxylase deficiency. J Clin Endocrinol Metab 1997; 82: 2097-2101.

23 Raghupathy R: Th1-type immunity is incompatible with successful pregnancy. Immunology Today 1997; 18: 478-482. 